\title{
How a Map with a Tour Route Recommendation Promotes Circuitous Tourism
}

\author{
Meng-Cong Zheng*1 \\ ${ }^{1}$ Associate Professor, Department of Industrial Design, National Taipei University of Technology, Taiwan, R.O.C.
}

\begin{abstract}
This study selected the Banqiao district of New Taipei City, Taiwan that is both an important transportation hub and diverse cultural area for tours as the place of study to explore the feasibility of promoting circuitous tourism through the recommendation of highly acclaimed tour routes. Both local residents and people who had never travelled to the Banqiao district were engaged in the study to determine their opinions on Banqiao tourist attractions, their tour route recommendations, and their participation in a travelling experiment in Banqiao. The results show that a map with a tour route recommendation could effectively reduce the frequency of tourists stopping temporarily to re-affirm their movement direction and the location of their destination. A map with a tour route recommendation also extends the time spent by visitors at the area, increases the number of tourist attractions visited and the distance they would travel, while retaining the same level of satisfaction as when they travel without the tour route recommendation. Participants who were using a map with a recommended tour route during their tour experiments created a more accurate handdrawn cognitive map. Maps with tour route recommendations improved the participants' spatial cognition of the region.
\end{abstract}

Keywords: map design; circuitous movements; tour route recommendation

\section{Introduction}

Currently, as tourism has become one of the main economic activities of many countries, a tour map, which is an essential tool for travelling, could enhance the efficiency of travelling and promote the tourism industry for that region. The Banqiao (板橋) district of New Taipei City, Taiwan, is one of the important satellite cities located in northern Taiwan. Banqiao covers a total area of 23.14 square kilometres, and is an entirely flat terrain, suitable for human settlement, and is surrounded by rivers. Banqiao has an estimated population of 556,000. Within the Banqiao district, Banqiao Station is an important transportation hub that integrates the three major public transportation services, namely the Taiwan high-speed rail service, the Taiwan railway service, and the Taipei Metro service, all at one place.

In the past, the name of Banqiao was Fangchiao ( 板 橋). Because the pronunciation of Fangchiao sounded like the Japanese term for 'looking homeward' ( 望鄉), to prevent the Japanese people in Taiwan from thinking of their homeland, the Japanese government renamed it

*Contact Author: Meng-Cong Zheng, Associate Professor,

National Taipei University of Technology,

1, Sec. 3, Chung-hsiao E. Rd., Taipei, 10608, Taiwan, R.O.C.

Tel: +886-2-2771-2171 \#2827 Fax: +886-2-2731-7183

E-mail: zmcdesign@gmail.com

(Received October 8, 2014 ; accepted February 19, 2015)
Banqiao during the Japanese occupation period. Under the Banqiao government's active efforts to retain local cultures, the historical Lin Family Mansion and Garden was restored and has become a popular and well-known monument and tourist attraction. In such a city coupled with a diverse cultural heritage and modern economic vibrancy, a visitor could experience both the prosperity of the city and its ancient humanistic atmosphere. Banqiao has a somewhat constant number of visitors and provides various forms of art performances and activities. With the timely completion of its transport system, attracting more visitors to obtain a localized experience of Banqiao is a public design challenge.

Mathieson and Wall (1982) claimed that a tour refers to the temporal travelling of people away from their daily work and residential area to a tour area. A tour covers the types of tour activities involved, as well as facilities that cater to travelling needs. Circuitous tourism refers to the degree of tourists patronizing the shopping districts, the shops back and forth, retracing their routes and the degree of knowing the area they are visiting through such circuitous movements. There are four essential factors that could promote circuitous movement (Suzuki et al., 2010).

1. A well-defined urban space, where visitors travelling on foot are able to know their exact location and the direction they are heading to.

2. Charming tourist attractions, as visiting a good tourist attraction is one of the main objectives of circuitous tours. 
3. Connectivity within the city, as it is essential to link up various standalone tour locations to encourage circuitous movements over a larger area.

4. A good tour map, which provides useful information to a visitor who tours the city on foot. It would affect the visitor's circuitous movements within the city, and therefore the essential information selected and placed in the map is a key factor to promote circuitous tourism.

Providing new tour information is an important factor in promoting the frequency of circuitous tour movements. Also, information intended for circuitous tour movements, in comparison with inductive tour information, provides richness and freedom of choice, though it might not indicate the shortest travelling route (Suzuki et al., 2010). Passini (1992) stated that wayfinding is a complex activity, as it involves planning, decision-making and information crunching, and all these depend on the mental ability to understand and handle complexity. Such ability is known as spatio-cognitive ability, which enables us to understand the spatial environment and move about successfully within a space.

A cognitive map is a visual representation of one's environmental psychological state. It requires experience to build a cognitive map, as it represents the accumulation and collective record of experience within the environment. In other words, it is the person's constructive knowledge of a familiar environment (Kaplan \& Kaplan, 1982). In general, people with greater familiarity of an environment would produce a more accurate and detailed cognitive map of that environment, and it would have a higher resemblance to a real map (Evans et al., 1980). According to Evans and other researchers, our cognition of an environment originates from the spatial information of maps, personal experience of the environment and information from other sources.

Banqiao, bearing a unique urban image of both an important heritage city and a convenient transportation hub, is therefore selected for carrying out this study. Through experiments of ranking Banqiao tourist attractions, a tour route recommendation and testing a tour using a map with a tour route recommendation, this study examines whether provision of a tour route recommendation could promote circuitous tour movements. The findings of this study could be used as a reference for future map design purposes. This study focuses on the culturally-rich Banqiao district, which is also the highly connected transportation hub of New Taipei City, through conducting an awareness survey for both local residents and non-locals, a tour route recommendation study and mobility experiment using a tour route recommendation map, to understand whether provision of highly recommended tour routes could help visitors to enhance their tour experience in a localized circuitous tour.

\section{Method}

This study carried out three investigations: ranking Banqiao tourist attractions, a tour route recommendation and testing of a tour using a map with a tour route recommendation.

\subsection{Ranking of Banqiao Tourist Attractions}

This experiment was carried out to determine the public's preferences concerning Banqiao tourist attractions by gathering opinions from both local residents and non-locals. This study extracted 60 tourist attractions from an exploratory map developed by the Fangchiao Cultural Association for the ranking experiment (closed card sorting) (Boulton, 2007; Maurer \& Warfel, 2004; Morville \& Rosenfeld, 2006). During the experiment, participants were asked to rank the attractions based on their preferences, and to voice the reasons behind such ranking, and also give their impression concerning the attractions. The attractions were made into picture cards consisting of photographs and descriptive text (Fig.1.). Upon consultation with a local historical expert, the cards were divided into five main categories, namely "monument landmarks", "the olden days' way of living", "nature and recreation", "education and the humanities" and "religious cultures", according to the characteristics of the attractions.

Each participant was asked to rank the attractions within each of the categories. The local residents ranked the attractions from a perspective of introducing Banqiao to their friends for touring, while the nonlocals gave their rankings based on their interests in visiting the attractions. The process of ranking and reasoning was video recorded accompanied by written notes. A total of 20 local residents and 20 non-locals participated, which consisted of 10 males and 10 females in each set. The local residents were volunteers of the Fangchiao Cultural Association (40-60 years old), while the non-locals were people who had never toured the Banqiao district before at the point of the experiment (20-30 years old).

\subsection{Tour Route Recommendation}

Two sets of evaluation ratings of the 60 tourist attractions were created based on local residents and non-local participants' ranking results. Four persons who are familiar with Banqiao were asked to recommend tour routes for the area of Banqiao, with reference to the two sets of ratings of the 60 tourist attractions. They were free to decide whether to include or exclude the tourist attractions to create complete round trips. Then an evaluation table was produced for the tour routes drawn by the participants, and the evaluation covered four aspects:

a. Total walking distance of tour route;

b. Number of turns made to complete the tour route;

c. Number of tourist attractions covered; and

d. The total points obtained by summing up the points given to each tourist attraction covered based on its ranking position. 


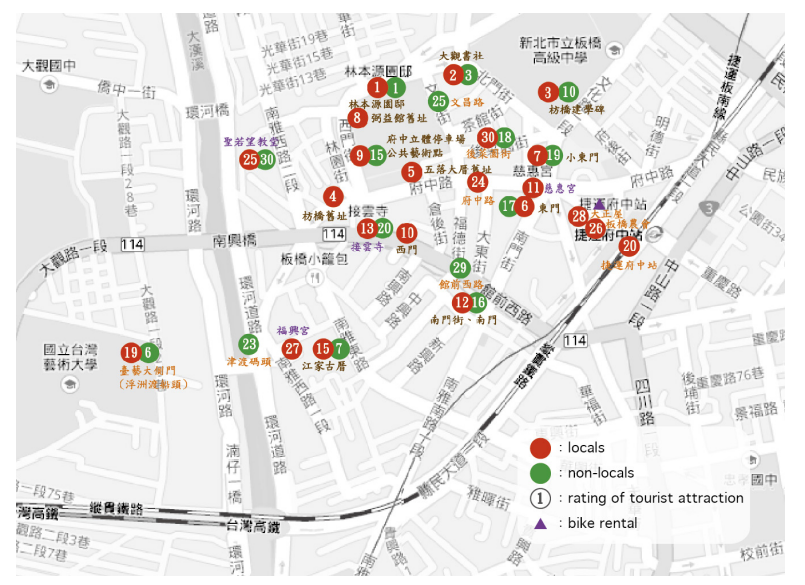

Fig.1. The Evaluation Rating of Tourist Attractions Around the Fuzhong Metro Station by Local Participants (in Red) and Non-Locals (in Green)

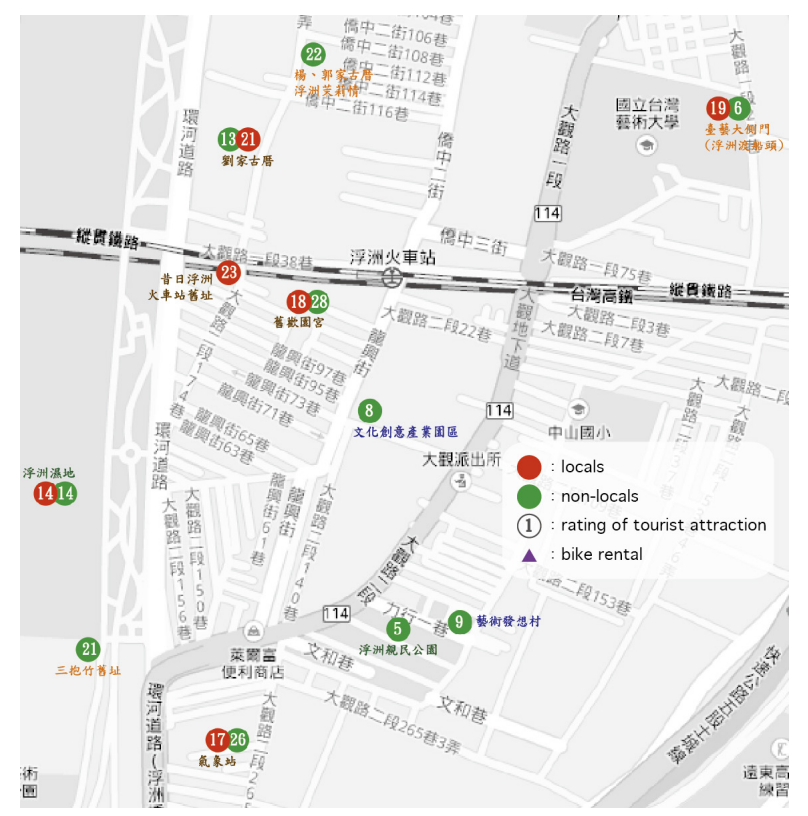

Fig.2. The Evaluation Ratings of the Attractions Around the Fuzhou Station According to Rankings by Local Participants (in Red) and Non-Local Participants (in Green)

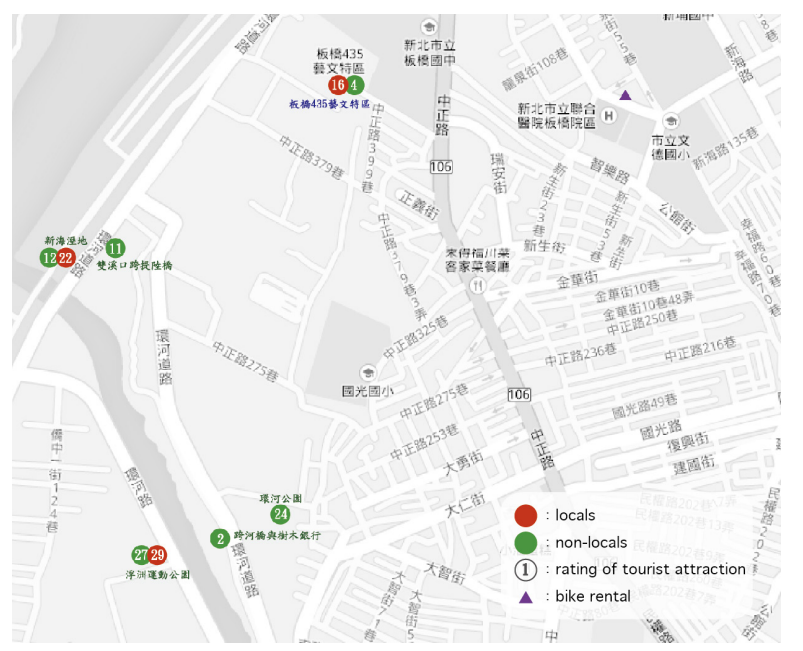

Fig.3. The Evaluation Ratings of Tourist Attractions within the 435 Arts District, According to the Ranking of Attractions by Local Participants (in Red) and Non-Local Participants (in Green)
There were five participants ranging between 20 and 40 years of old, and they were familiar with the experiment site. This study predefined the criteria of an ideal tour route as having the shortest travelling distance, the least number of turns, travelling through the most number of tourist attractions and having the highest overall attraction rating. The final rating of each tour route drawn by participants was then obtained through a formula that is a function of the points calculated for the four aspects above. The final tour route recommendation was selected based on the highest rating received by the tour route.

\subsection{Experiment of the Use of a Map with a Tour Route Recommendation}

This experiment aimed to determine the effectiveness of using a tour map containing a tour route recommendation in promoting circuitous tour movements, as well as to explore the differences in cognitive maps of participants' with or without the recommended tour route maps. The participants were divided into two groups: one with a basic map with only tourist attraction markers (Fig.2.), and one with a recommended tour route map (Fig.3.). The group of participants with the basic map was asked to plan their own tour route and then travel on foot according to their own plan (route planning; Golden, 1988). The group with a recommended tour route map was asked to travel according to the given route. Both groups of participants were required to return to the starting location at the end of the experiment. During the tour activity, the participants were not allowed to ask for directions or any aided navigation system, and their opinions concerning each visited attraction were voice recorded.

At the end of the experiment, each participant was asked to draw a map showing the route taken and the attractions he or she had visited during the tour activity. These hand-drawn cognitive maps by both groups of participants were then compared with their initially planned route and recommended route maps to understand their spatial cognitive differences (Lynch, 1960). The entire process of the experiment was video recorded and accompanied by written notes. Each group of participants consisted of five males and five females, making up a total of 20 participants for this experiment. All of them had never visited Banqiao, and their age ranged between 20 and 30 years.

This study uses the Relative Angle Segments (RAS) calculation method to find out if the provision of the recommended tour route would help tour visitors to determine their position at the tour area. The calculation is as follows: Objective Angle Segments (OAS) are the angle segments measured from the starting position, i.e. the Fuzhong Metro Station Exit 2 to each of the tourist attractions on the original maps given to participants. The Cognitive Angle Segments (CAS) were measured from the Fuzhong Metro Station Exit 2 to each of the tourist attractions marked by the 
participants on their cognitive maps. This method was modified from the method used by Rob Kitchin and Mark Blades (2002). The formula for calculating the RAS is as follows:

$$
\operatorname{RAS}=\left[\sum_{1-1}^{\mathrm{n}}\left(\frac{\text { OAS }- \text { CAS of each tour attraction }}{1.20}\right) \times 100\right] \div \mathrm{n}
$$

The number of angle segments with positioning errors (n) is the number of position deviated angles obtained by superimposing the cognitive maps of participants over the original tour map. The positioning deviated angles could have a positive or negative value for each attraction. Therefore, it is necessary to calculate the average deviation value for the RAS for a more accurate representation of the state of the participant's environmental cognition.

\section{Results and Discussion}

\subsection{Ranking of Banqiao Tourist Attractions}

The tourist attractions in the Banqiao district are located in three major tour areas, the first being around the Fuzhong Metro station, the second being around the Fuzhou station, and the third is around the 435 Arts District. On the map, the names of tourist attractions were marked in different colours: coffee brown represents a "monument landmark", green represents a place significant to "the olden days' way of living", blue represents "nature and recreation", purple represents a centre or an institution under the "educational and humanities" category, and orange represents a religious cultural site.

\section{A. Tour Area around Fuzhong Metro Station}

The first tour area around the Fuzhong metro station contains 25 tourist attractions, and according to both local and non-local participants, more than half of the top 30 tourist attractions are located in this area. Local participants recommended 22 of these attractions, which is more than the 15 attractions recommended by non-local participants. Most of all the participants felt that attractions located in this tour area have high tour value and were interested in visiting them. Local participants indicated that this area is historically meaningful to Banqiao, and the stories behind the attractions are also very remarkable. The non-local participants felt that the historical monuments in this area such as the Lin Family Mansion and Garden are still existing and worth visiting. Some streets, such as Wenchang Street, have a special atmosphere.

\section{B. Tour Area around Fuzhou Station}

The tour area around Fuzhou (railway) station contains 11 tourist attractions. Non-local participants recommended 10 of these attractions, which is more than the six attractions recommended by local participants. Non-local participants indicated their interest in the centres for education and humanities, and wished to see the centres organize events or exhibitions. Also, all participants expressed a similar opinion that it is not easy to have a large area of wetland or grassland in an urban city, thus they gave the Fuzhou Wetland and Fuzhou People's Park high rankings.

\section{Tour Area around the 435 Arts District}

The tour area around the 435 Arts District contains six tourist attractions, i.e. the least number of attractions among the three tour areas. Non-local participants recommended more attractions, which are all six attractions compared to only three attractions recommended by local participants. The 435 Arts District is particularly interesting and recommended by both the local and non-local participants, having a ranking of $16^{\text {th }}$ and $4^{\text {th }}$ respectively. There are unique architecture and arts activities in the 435 Arts District that attract both national and international artists to set up their studios there. Non-local participants expressed that they might gain a lot from visiting the 435 Arts District, while local participants said that there is plenty of free space within the 435 Arts District for children to have fun, and they would also recommend their friends to go there for arts activities.

Overall, non-local participants have high interests in tourist attractions in the "nature and recreation" category, with 7 out of 10 tourist attractions that they had ranked in the top 30 belonging to this category. Among the three tour areas, the area around Fuzhong Metro station has the most number of recommended tourist attractions, and these attractions also have higher evaluation ratings. The main reason for recommending these attractions, according to the participants during the experiment, is that the attractions in this tour area are highly representative of Banqiao's historical development and thus have great historical meanings for the locals. Among the attractions, the Lin Family Mansion and Garden is the most highly acclaimed monument, and could be of high interest to non-local visitors from a tour perspective. Therefore, this study chose the tour area around the Fuzhong Metro station as the area to proceed with the next experiment.

\subsection{Recommendation of Tour Route}

Using the tour area around the Fuzhong Metro station as the area of study, five tour routes were recommended by participants who were familiar with the Banqiao area with reference to the rankings of tourist attractions. These routes were evaluated over four criteria, namely total walking distance, number of turns into different paths, number of tourist attractions covered and sum of evaluation ratings of those attractions, with a highest point of 5 and lowest point of 1 given per criterion. The route with the highest sum of points would be selected as the final route recommendation to be used on the tour map.

Base on the tabulated results, the best-rated tour route recommended is Route 1 . This route starts according to the direction faced by Exit 1 of the Fuzhong Metro station, moves along Xianmin Boulevard Section 1, through Guanqian West Road, Nanya West Road and Fuzhong Road, then continues 
Table 1. Comparison of Findings from Group 1 and Group 2

\begin{tabular}{|c|c|c|c|c|c|c|c|c|}
\hline \multirow[b]{2}{*}{$\begin{array}{l}\text { Items } \\
\text { compared }\end{array}$} & \multicolumn{4}{|c|}{$\begin{array}{l}\text { Group } 1 \\
\text { (with route recommendation) }\end{array}$} & \multicolumn{4}{|c|}{$\begin{array}{l}\text { Group } 2 \\
\text { (without route recommendation) }\end{array}$} \\
\hline & Time spent & $\begin{array}{l}\text { No. of } \\
\text { attractions }\end{array}$ & No. of stops & $\begin{array}{l}\text { Walking } \\
\text { distance }\end{array}$ & Time spent & $\begin{array}{l}\text { No. of } \\
\text { attractions }\end{array}$ & No. of stops & $\begin{array}{l}\text { Walking } \\
\text { distance }\end{array}$ \\
\hline Average & $70.4 \mathrm{~min}$ & 23.7 & 4 & $3133.5 \mathrm{~m}$ & $56.5 \mathrm{~min}$ & 17.4 & 5.7 & $2470.6 \mathrm{~m}$ \\
\hline
\end{tabular}

through Wenhua Road Section 1, Wenchang Street, Ximen Street, and finally returns to Fuzhong Metro station. The tourist attractions covered in this route include the Lin Family Mansion and Garden, some of the most established and popular ancient Chinese temples, a unique Catholic church with traditional Chinese architectural style, and other representative attractions. This study thus proceeded with the final experiment based on this recommended tour route.

\subsection{Experiment of Maps with and without Tour Route Recommendations}

In this experiment, participants were divided into two groups to execute the tour activity on foot. Group 1 was given a tour map with route recommendation, while Group 2 was given a map without a tour route recommendation. Tourist attractions were marked on both maps, and all participants started their tour activity from Fuzhong Metro station and also ended the activity back at the same station. Group 1 participants were told to follow the given tour route for the activity, while Group 2 participants were told to plan their own tour route. During the experimental tour the activity, the time spent for tour, number of tourist attractions visited, number of stops (to determine their location and direction) made, and the route actually taken were recorded. The participants were required to voice aloud their feelings and opinions concerning the tourist attractions and the environment during the activity. After the activity, they were given white sheets of paper to draw their cognitive map of the route they have taken and mark the positions of the tourist attractions visited. The cognitive maps were then compared with the original given tour map to evaluate the environmental cognitive differences between Group 1 and Group 2.

A. Differences in circuitous movements between the two groups

Results shown in Table 1. indicate that Group 1, being given the tour route recommendation, spent more time at the tour area compared to Group 2 (70.4 min and 56.5 min respectively). The number of tourist attractions visited by Group 2 and its average walking distance were also less compared to Group 1. In contrast, the average number of stops made by Group 2 participants to determine location and direction, i.e. 5.7 times, is more than the average number of stops made by Group 1, which is 4 times. Thus the results indicated that given a map with a tour route recommendation, participants could reduce the number of stops they need in determining their travelling direction, as well as locating their destinations. Overall, Group 1 participants spent more time (70.4 min $>56.5$ $\mathrm{min})$ at the tour area, completed a longer walking distance (3133.5 m>2470.6 m) and visited more tourist attractions $(23.7>17.4)$. The experiment results thus showed that by providing a tour route recommendation in the map, participants found it easier to move about in the tour area, and also lengthened the amount of time spent in circuitous movements, thereby successfully increasing their chances of having greater experiences at the tour area.

\section{B. Comparison of cognitive maps between Group 1 and Group 2}

This study used the Relative Angle Segment (RAS) calculation method (Kitchin and Blades, 2002) to obtain the angular positioning of tourist attractions marked by the participants in their cognition maps, to determine the influence a map with a recommended tour route had on cognition maps. Tables 2. and 3 . showed that both groups of participants had positioning errors of the tourist attractions they marked on their cognition maps; specifically, all the angles measured between the tourist attractions on the cognitive maps were bigger than those from the objective angles measured on the actual given tour maps. However, the errors as indicated with the RAS value for Group 1 who used the map with a tour route recommendation is smaller compared to that of Group 2, having the RAS values $|-1.09|<|-3.8|$ respectively. Thus Group 1, who were given a tour route recommendation, actually created more accurate cognitive maps compared to the cognitive maps of Group 2. Table 4. indicates that both groups of participants were able to mark at least half of the tourist attractions found on the original given tour maps, with Group 1 indicating 54\% of attractions and Group 2 indicating 59\% of tourist attractions on their cognitive maps. The public could roughly recall more than half of the total tour attractions they had visited, but those with a tour route recommendation map travelled a longer distance than those without.

\section{Analysis from the think-aloud results}

Everything that the participants said during the tour activity was recorded and coded into two major categories: their feelings towards the tourist attractions and their feelings concerning the environment they are moving through.

\section{(a) Comments on tourist attractions}

The participants felt that the tourist attractions should have more signs and descriptive text about them. Some tourist attractions where ancient architecture had already been torn down should at least show historical photographs of the original scenes of the past and present so that visitors would not be disappointed upon reaching the location. In addition, 
Table 2. Relative Angle Segments (RAS) for Group 1 (with route recommendation)

\begin{tabular}{lll}
\hline & Gender & RAS \\
\hline P1 & F & -3.63 \\
\hline P2 & F & 4.04 \\
\hline P3 & F & -0.01 \\
\hline P4 & F & -5.35 \\
\hline P5 & F & 1.95 \\
\hline P6 & M & -1.16 \\
\hline P7 & M & -2.29 \\
\hline P8 & M & -5.51 \\
\hline P9 & M & -8.34 \\
\hline P10 & M & 9.34 \\
Average & & -1.09
\end{tabular}

Table 3. Relative Angle Segments (RAS) for Group 2 (without route recommendation)

\begin{tabular}{lll}
\hline & Gender & RAS \\
\hline P1 & F & 0.38 \\
\hline P2 & F & -4.58 \\
\hline P3 & F & -2.12 \\
\hline P4 & F & -3.15 \\
\hline P5 & F & -2.63 \\
\hline P6 & M & -5.52 \\
\hline P7 & M & -3.29 \\
\hline P8 & M & -4.61 \\
\hline P9 & M & -4.18 \\
\hline P10 & M & -8.3 \\
Average & & -3.8
\end{tabular}

participants gave a positive evaluation of Wenchang Street for its classic and elegant ambience. However, they expressed their concern for safety as motorbikes were allowed in the narrow street, and suggested that this street be converted to a pedestrian walkway. The number of positive comments on tourist attractions given by both groups is the same.

\section{(b) Environment of the streets}

Participants felt that some parts of the route where the market vendor stalls occupy spaces on pedestrian walkways were very narrow and thus difficult to walk through. The area around the market was also dirtier and chaotic, and vehicles were also parked illegally, causing disconnections of sections of the pedestrian walkway in the tour area. Visitors were confused over where to continue with their route when they encountered a disconnection of the pedestrian walkway. However, some participants also felt that the way the market stalls were placed and operated and their specialties made up the special features of the tour area, so they were not overly concerned with the narrow walkway because it is a special taste of the local culture. The group that was not provided with a tour route recommendation gave more positive comments concerning the street environment than the

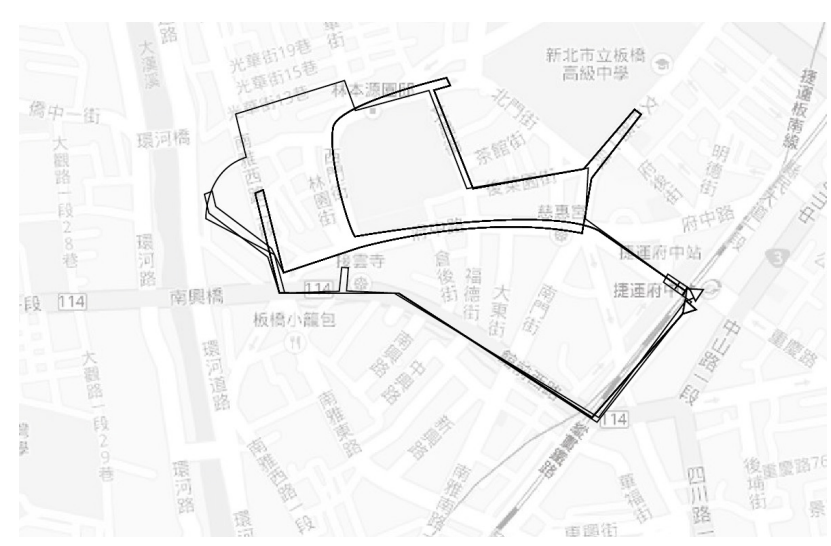

Fig.4. Wayfinding with Sightseeing Route Recommendation (Group 1)

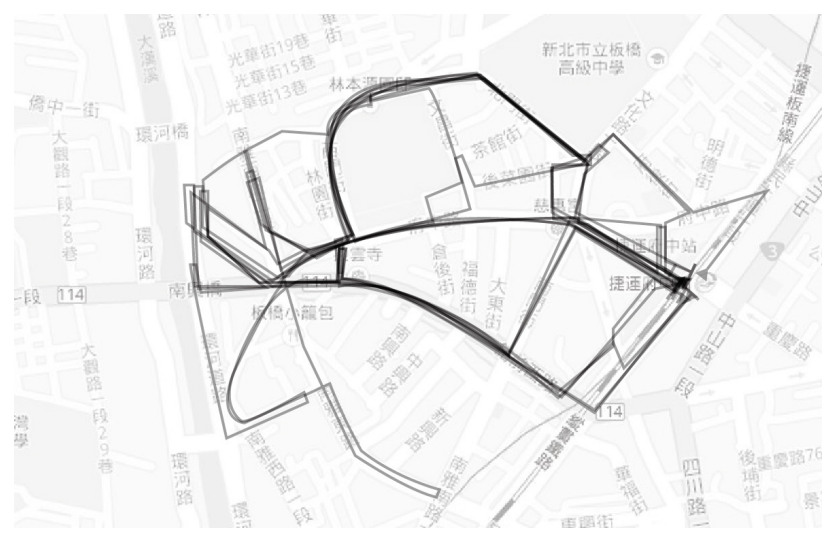

Fig.5. Wayfinding without Sightseeing Route Recommendation (Group 2)

group with a tour route recommendation map.

Group 1 participants, who were given a map with a recommended tour route, stayed longer at the tour area, visited more tourist attractions and walked a longer distance compared to Group 2 who were not given a recommended route. Group 1 also made less stops during the tour activities to determine the location of their destination or direction compared to Group 2. The cognitive maps of Group 1 participants were more accurate than Group 2, indicating that provision of a tour route recommendation is effective in helping visitors build their environmental cognition. The shapes of cognition maps drawn by Group 1 participants resembled the shape of the given recommended route, while the shapes of cognition maps of Group 2 had more variations. Cognition maps of Group 1 were about the same size, while the cognition maps of Group 2 had a bigger discrepancy in size. Although this study showed that provision of a recommended tour route is effective in increasing circuitous movements within the tour area, participants expressed that due to a lack of sufficient information

Table 4. Percentage of Tourist Attractions Visited by the Two Groups of Participants

\begin{tabular}{cccc} 
& Average number of attractions visited & $\begin{array}{c}\text { Average number of attractions marked on } \\
\text { cognitive maps }\end{array}$ & Percentage \\
\hline Group 1 & 23.7 & 12.8 & $54 \%$ \\
\hline Group 2 & 17.4 & 10.3 & $59 \%$ \\
\hline
\end{tabular}


about the tourist attractions and the actual condition of the environment, they spent more time than expected to determine their location, therefore reducing their willingness to visit the tourist attractions. Also, although the duration of the visitors' stay and the number of tourist attractions visited were more for the group with the use of a tour route recommendation, the amount of positive feedback received from both groups was the same (15 times). Among the group that was given a tour route recommendation, some participants mentioned that they were more used to walking for at most 30 minutes, but the recommended route took close to an hour, thus affecting their tour experience. This shows that although the recommended route could encourage a circuitous tour, it may not necessarily suit the walking preferences and habits of individuals; the recommended route still has room for improvement.

The participants who used the tour route recommendation map covered the same area in their travelling experiment. While travelling, there were occasions when they were attracted by other things and strayed off the track. However, those without a recommended route may not necessarily know how to plan their travelling route, thus they tend to travel a wider area. Some participants also returned to the starting location without visiting all the marked attractions. Those given a recommended tour route behaved more uniformly, and were more able to finish visiting all the attractions. (Figs.4. and Fig.5.)

\section{Conclusion}

This study revealed that the tourist attractions recommended by local and non-local participants concentrated around the Fuzhong Metro station. These attractions were significant and representative of the history of the Banqiao district. The Lin Family Mansion and Garden were completely restored and was the most recommended by local participants and also the most sought after attraction among nonlocal participants. In defining the recommended tour route, this study used walking distance, number of turns, number of tourist attractions and preferential advantage of attractions. To avoid visitors losing their sense of direction after leaving the metro station, the recommended route adhered to the principle of having a lesser number of turns by starting from the direction faced by the metro station exit and proceeding along Xianmin Boulevard Section 1.

In the experiment for testing effects of the recommended tour route on circuitous movements, the results showed that provision of the recommended route helped participants make less stops during the tour activities to determine the location of their destination or direction, and the participants also remained longer in the tour area, visited more tourist attractions and walked a longer distance. The participants with a recommended route also demonstrated better environmental cognition with their cognitive maps.
When visitors set a 'tour' as their objective, a walking time of 10 minutes or more could cover a distance of at least 402 meters (Yang \& Diez-Roux, 2012). The tour route recommendation for different tour areas should take into consideration visitors' walking distance and adding venues for rest appropriately to help the visitors enjoy the tour experience in the area at a relaxed pace, to avoid unnecessary increase in travelling time spent while following the recommended tour route.

The participants' thinking aloud records indicated that signs for tourist attractions at the tour area should be increased and with more detailed descriptions. The participants also hoped that the problem of tour streets being shared by pedestrians and vehicles should be addressed so that pedestrians could be more assured of their safety. Furthermore, tour maps could show photographs of the past and present appropriately with a short explanatory description to help visitors know more about the tourist attractions. Photos of the present could help visitors spot the tourist attractions more easily, while photos of the past could provide a deeper understanding of the attraction. Tourist attractions recommended in the tour map should make reference to the opinions of local residents who know the cultural background of the area well, as well as opinions of visitors, and thus would encourage more interactions between visitors and local residents. For example, the tour route recommendation could be based on different needs of people in terms of mobility, season, activity schedule, etc., to be more flexible when providing travelling options. Furthermore, future research will focus on the visual presentation method of the tour route recommendation, such as the effects of solid and dashed curves, whether there is a need to use arrows to indicate the direction for the next destination, and in what ways should arrows be drawn to be easily interpreted by visitors.

\section{References}

1) Appleyard, D. (1970) Styles and methods of structuring a city. Environment and Behavior, 2(1), pp.100-177.

2) Appleyard, D. (1976) Planning a pluralistic city. Harvard-MIT Joint Center for Urban Studies Series.

3) Arthur, P. and Passini, R. (1992) Wayfinding-People, Signs, and Architecture. New York: McGraw-Hill.

4) Arthur, P. and Passini, R. (2002) Wayfinding: People, Signs, and Architecture. New York: McGraw-Hill.

5) Best, G. (1970) Direction-finding in large buildings. In D. Canter (ed.) Architectural Psychology. London: RIBA Publication, pp.72-75.

6) Chen, H.-Y. and Zheng, M.-C. (2013) Individual differences in map reading for designing maps - Banqiao, Taiwan as a case study. $5^{\text {th }}$ International Congress of International Association of Societies of Design Research, pp.4874-4884.

7) Eaton, G. (1992) Wayfinding in a library: Book searches and route uncertainty. RQ, 30(4), pp.523-525.

8) Evans, G.W. and Pezder, K. (1980) Cognitive mapping: Knowledge of real-world distance and location information. Journal of Experimental Psychology: Human Learning and Memory, 6, pp.13-24.

9) Evans, G.W. and Wood, D. (1981) Assessment of environmental aesthetics in scenic highway corridors. Environment and Behavior, 12, pp.255-273. 
10) Kaori, H. (2011) On the influence of a city map as a guide for rambling downtown beyond main streets: On the citizen's rambling activity in urban streets and their spatial cognition (Part 8). Summaries of technical papers of the Annual Meeting Architectural Institute of Japan. F-1, Urban Planning, Building Economics and Housing Problems, pp.213-214.

11) Kaplan, S. and Kaplan, R. (1982) Cognition and Environment. New York: Praeger.

12) Kitchin, R. and Blades, M. (2002) The cognition of geographic space. London: I.B. Tauris.

13) Lawton, C.A. and Kallai, J. (2002) Gender differences in wayfinding strategies and anxiety about wayfinding: a crosscultural comparison. Sex Roles, 47, pp.389-401.

14) Lee, Y.-J. (1990) Cognitive map and preference matrix-An introduction to the study of environmental psychology. Journal of Building and Planning, 5, pp.133-140.

15) Passini, R., Proulx, G. and Rainville, C. (1990) The spatiocognitive abilities of the visually impaired population. Environment and Behavior, 22, pp.91-118.

16) Punnoi, N., Kubota, A., Suzuki, R., Sakuraba, K. and Okuma, M. (2010) Analysis of promoting factors for visitors' rambling activities: A study for the improvement of visitors' rambling activities in historic area in Sawara (Part 1). Summaries of technical papers of the Annual Meeting Architectural Institute of Japan, pp.557-558.

17) Ryohei, S. (2010) A social experiment aimed for the improvement of visitors rambling activities and the consciousness of inhabitants about Machizukuri: A Study for the improvement of visitors rambling activities in Sawara historic area (Part 2). Summaries of technical papers of the Annual Meeting Architectural Institute of Japan. F-1, Urban Planning, Building Economics and Housing Problems, pp.559-560.

18) Sakuho, S. (2006) On the circuit system and urban environmental formation in urban tourism vol. 3: On the visibility for tourist passage. Architectural Institute of Japan, 46, pp.337-340.

19) Sakuraba, K., Okuma, M., Kubota, A., Suzuki, R. and Punnoi, N. (2010) Strategy of gradual rambling activities and rambling activities sign plan: A study for the improvement of visitors' rambling activities in historic area in Sawara (Part 3). Summaries of technical papers of the Annual Meeting Architectural Institute of Japan, pp.561-562.

20) Satoru, I. (2010) An influence of referring city map while rambling on the extension of one's rambling area: On the citizen's rambling activity in urban streets and their spatial cognition (Part 6). Summaries of technical papers of the Annual Meeting Architectural Institute of Japan. F-1, Urban Planning, Building Economics and Housing Problems, pp.377-378.

21) Suzuki, R., Sakuraba, K., Kubota, A., Okuma, M. and Punnoi, N. (2010) A social experiment aimed for the improvement of visitors rambling activities and the consciousness of inhabitants about Machizukuri: A study for the improvement of visitors rambling activities in Sawara historic area (Part 2). Summaries of technical papers of the Annual Meeting Architectural Institute of Japan, pp.559-560.

22) Takashi, S. (2005) On the circuit system and urban environmental formation in urban tourism vol. 2: On practical use of historical heritage for urban tourism in Himeji. Architectural Institute of Japan, 45, pp.485-488.

23) Tsuguo, I. (2001) Symbol Signs for Public Information. Japan: Dai Nippon Printing Co., Ltd.

24) Yang, Y. and Diez-Roux, A. V. (2012) Walking distance by trip purpose and population subgroups. American Journal of Preventative Medicine, 43(1), pp.11-19.

25) Yuichi, S. (2007) The visual information which encourage or restrain citizens' strolling activities in urban space: on the relationship of strolling activities and visual information given by the environment in downtown Kumamoto (Part 2), pp.191-197.

26) Zheng, M.-C. (2008) Information signs based on users' wayfinding behavior in transfer between aboveground stations. Japanese Society for the Science of Design, 55(6), pp.1-10. 